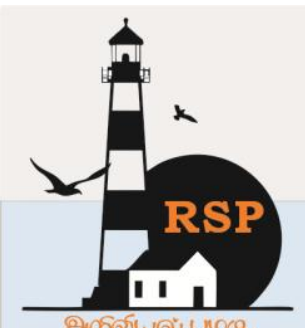

INTERNATIONAL RESEARCH JOURNAL ON

e-ISSN : 2582 - 4376 ADVANCED SCIENCE HUB Open Access

RSP SCIENCE HUB

(The Hub of Research Ideas)

Available online at www.rspsciencehub.com

\title{
Smart Dust Bin for Modern Environment
}

S.Divya ${ }^{1}$, M.Mohan ${ }^{2}$, S.Dhivya ${ }^{3}$, B.Prasath ${ }^{4}$

1,2,3,4 Assistant Professor Department of Information Technology, SNS College of Technology, Coimbatore, India.

m.mohansan@gmail.com ${ }^{1}$

\begin{abstract}
Nowadays all types of garbage are dumped into the dustbin at the buildings (houses), hospitals etc., Hence it is difficult to segregate it. To avoid all such problems, we are going to implement a project where segregation of wet, dry, plastics and metallic wastes automatically using automated smart dust bin and afterwards signal is sent to the Mobile phones. The automated smart dust bin has several features and the main feature of it is to separate the waste automatically. The bin will have four compartments for the segregation of the wastes: for plastic waste, for wet waste, for dry waste and finally for the metallic wastes. Apart from this the bin will have motor for the rotation of the bin. This project makes it hands-free and evidently more hygienic method of separation. The bin will also notify about the amount of wastes filled through an LED. The bin will also alert by sending a message to phone to tell that it is time to throw the garbage. This idea will help us to dispose the waste in a hygienic manner. This project mainly concentrates on domestic wastes whose value is unrecognized since people do not spend time in separating the wastes. Instead of sending them to municipal corporation, waste can be sent directly for recycling if waste is separated at household level.
\end{abstract}

Keywords: Segregation, Capacitive, Automation, GSM Module, Arduino UNO.

\section{Introduction}

Rapid increase in population had led to improper waste management in metro cities and urban areas which has resulted in spreading of diseases. The segregation, transport, handling and disposal of waste must be managed properly to minimize the risks to the public and the environment. Waste segregation is an absolutely necessary stage in waste management. Most of the waste is sent directly to the landfills without proper sorting and this has caused a huge loss for us. Properly distinguishing wet, dry, plastic and metallic waste, lets us to recycle it more efficiently and it saves us a lot of money and resources. And the wet waste can be used as compost. With the advent of the plastic ban and people having so many plastics in their households, Automated smart dust bin can help dispose of the waste properly and efficiently without any problems. The wet waste can be used as compost and some of the dry wastes can be recycled. Automated smart dust bin identifies the type of waste and segregates it using the techniques mentioned. The bin can help us to dispose the waste properly and efficiently without any problem. Some of the dry wastes can be recycled. This identifies the type of waste and segregates it using the techniques mentioned. [1-5]

Thus they are protected from unwanted smell, toxicity and various diseases. Segregation makes it possible to reuse and recycle the waste effectively. Thus implementing our project at 
household level will reduce the expenditure on waste disposal, manual effort.

\section{Objectives of Automated Smart Dust Bin}

The main objectives of AUTOMATED SMART DUST BIN are:

- Waste Segregation.

Automated smart dust bin segregates the waste into 4 types: Dry, Wet, Plastic and metals.

- Waste identification

The waste can be identified using IR sensor and its capacitive values.

- Recycling

The waste that can be recycled will be identified by its capacitive values and sending the values to some app or to some devices which will tell the user if that waste can be recycled or not based on some pre-given data.

- Re-usability

Identification of waste that can be used again and reused.

\section{- Waste Predication and Optimization}

By getting the network from the automated smart dust bin which is sent to the GSM module, it is able to distinguish all kinds of pattern and accordingly the waste is thrown into the particular bin and thus sent the garbage compartments in the most optimized path, which is more cost effective and also save fuel and resources.

\section{System Design:}

\section{a.IR Sensor:}

The IR sensor Infrared Light Which is either absorbed by the material (Waste) or Reflected. The Sensor also consists of an IR receiver which measures the reflected Infrared Light. The 20 receiver is connected to the ADC module of the Microcontroller which the Micro-controller which converts the analog signal to digital signal which is analyzed and used to determine the type of waste. The IR sensor is also used as a proximity sensor for detecting whether the segregation chamber is filled or not.

\section{b. Capacitive Sensors}

Capacitive sensors are most often used to measure the change in position of a conductive target. But capacitive sensors can be effective in measuring presence, density, thickness, and location of nonconductors as well. Non- conductive materials like plastic have a different dielectric constant than air.

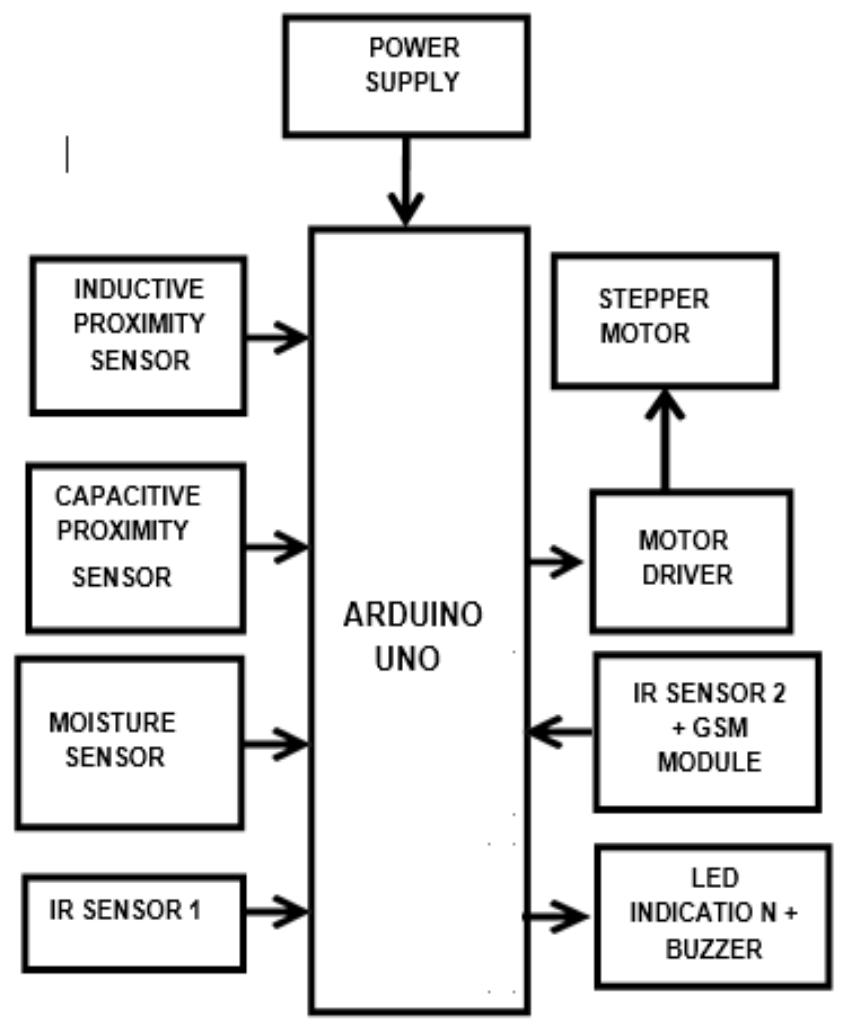

Fig 1: Block Diagram

\section{c. GSM Module:}

GSM is a mobile communication modem, it stands for Global System for Mobile communication (GSM). It is widely used as mobile communication in the world. GSM is an open and digital cellular technology used for transmitting mobile voice and data services operates at the $850 \mathrm{MHz}, 900 \mathrm{MHz}, 1800 \mathrm{MHz}$ and $1900 \mathrm{MHz}$ frequency bands. GSM system was developed as a digital system using Time Division Multiple Access (TDMA) technique for communication purpose.

\section{d. stepper Driver and Stepper Motor:}

Stepper driver is used to drive the stepper motor using the microcontroller. The waste chamber is mounted on the stepper motor which aligns the respective sections (Dry, Wet and Plastic) under the capacitive plates.

\section{e. Indication LEDs:}

These LEDs are directly controlled by the microcontroller for displaying the status of the 
www.rspsciencehub.com

system. For indicating bin is full, Bluetooth Status indicator, for indicating the type of waste.

\section{Design requirements:}

\section{a. Arduino Uno}

Arduino Uno is used in Do-it yourself projects proto typing. In developing projects based on codebased control. Development of automation system. Designing of basic circuit designs.

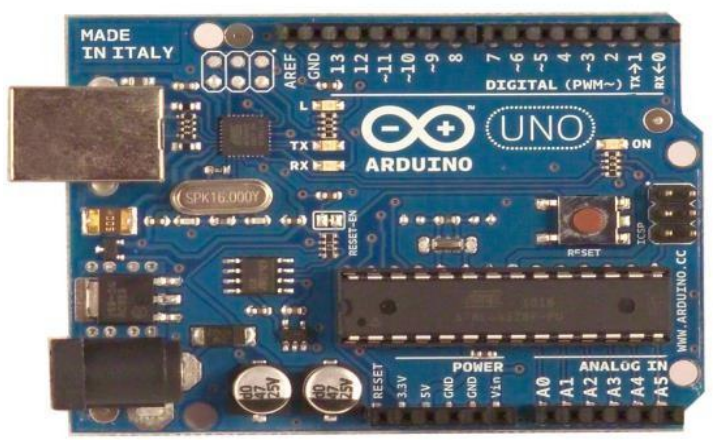

Fig.2.Arduino Uno

\section{b. Technical Specification}

\begin{tabular}{|l|l|}
\hline $\begin{array}{l}\text { Microcontroller AT } \\
\text { mega }\end{array}$ & 328 \\
\hline Operating Voltage & $5 \mathrm{~V}$ Input \\
\hline $\begin{array}{l}\text { Voltage } \\
\text { (recommended) }\end{array}$ & $7-12 \mathrm{~V}$ \\
\hline Input Voltage (limits) & $6-20 \mathrm{~V}$ \\
\hline Digital I/O Pins & $\begin{array}{l}14 \text { (of which 6 provide } \\
\text { PWM output) }\end{array}$ \\
\hline Analog Input Pins & 6 \\
\hline DC Current per I/O Pin & $40 \mathrm{~mA}$ \\
\hline $\begin{array}{l}\text { DC Current for 3.3V } \\
\text { Pin }\end{array}$ & $50 \mathrm{~mA}$ \\
\hline
\end{tabular}

\section{c. Infrared Radiation Sensors}

This device emits and detects infrared radiation. Generally, thermal radiation is emitted by all the objects in the infrared spectrum. paper

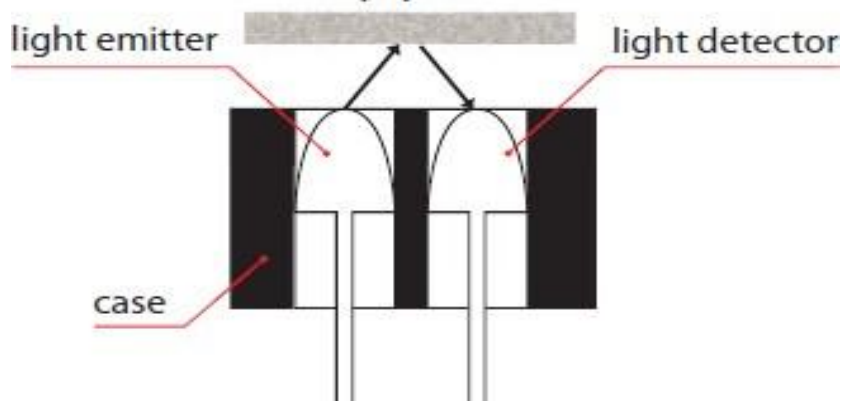

Fig.3. Infrared Radiation Sensors

\section{d. Capacitive Sensors}

Capacitive sensors are most often used to measure the change in position of a conductive target.[6]

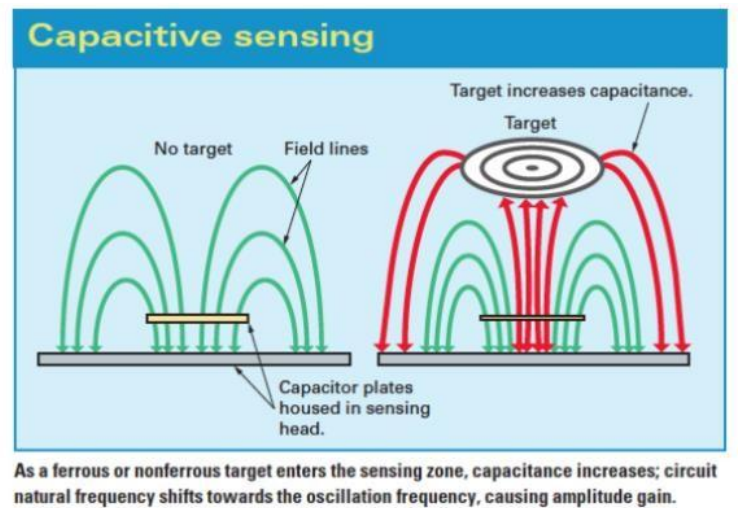

Fig.4.Capacitive Sensors

But capacitive sensors can be effective in measuring presence, density, thickness, and location of non-conductors as well. Nonconductive materials like plastic have a different dielectric constant than air.

\section{e. Metal Detector}

A metal detector is an electronic instrument that detects the presence of metal nearby. Metal detectors are useful for finding metal inclusions hidden within objects, or metal objects buried underground.

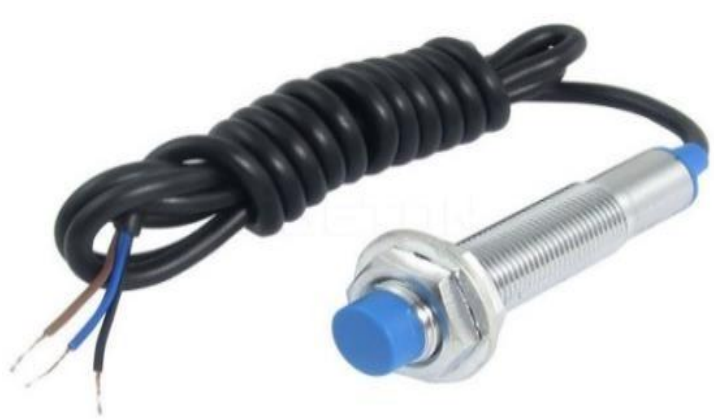

Fig.5.Metal Detector

They often consist of a handheld unit with a sensor probe which can be swept over the ground or other objects. If the sensor comes near a piece of metal this is indicated by a changing tone in earphones, or a needle moving on an indicator.

\section{f. Driver Motor}

L293D is a typical Motor driver or Motor Driver IC which allows DC motor to drive on 
either direction. L293D is a 16-pin IC which can control a set of two DC motors simultaneously in any direction. It means that you can control two DC motor with a single L293D IC.

\section{g.GSM Module:}

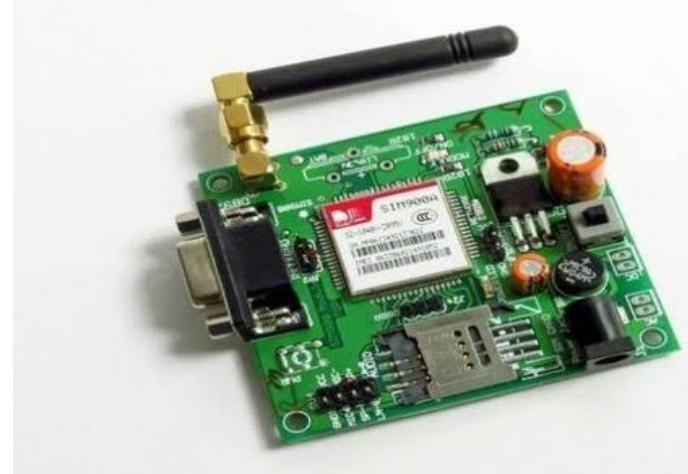

Fig.6.GSM Module

GSM is a mobile communication modem, it stands for Global System for Mobile communication (GSM). It is widely used as mobile communication in the world. GSM is an open and digital cellular technology used for transmitting mobile voice and data services operates at the $850 \mathrm{MHz}, 900 \mathrm{MHz}, 1800 \mathrm{MHz}$ and $1900 \mathrm{MHz}$ frequency bands.GSM system was developed as a digital system using Time Division Multiple Access (TDMA) technique for communication purpose. A GSM digitizes and reduces the data, then sends it down through a channel with two different streams of client data, each in its own particular time slot. The digital system has an ability to carry $64 \mathrm{kbps}$ to $120 \mathrm{Mbps}$ of data rates.

\section{Software Requirement:}

\section{Arduino IDE}

The Arduino Integrated Development Environment (IDE) is a cross- platform application (for Windows, macOS, Linux) that is written in functions from $\mathrm{C}$ and $\mathrm{C}++$. It is used to write and upload programs to Arduino compatible boards, but also, with the help of 3 party cores, other vendor development boards. The source code for the IDE is released under the GUN General Public License, version 2. The Arduino IDE supplies a software library from the wiring project, which provides many common inputs and output procedures. Userwritten code only requires two basic functions, for starting the sketch and the main program loop, that are compiled and linked with a program stub main into an executable cyclic executive program with the
GUN toolchain, also included with the IDE distribution.

\section{Proposed Method:}

The different types of garbage's are dumped into the dustbin at the buildings (houses), hospitals etc., Hence it is difficult to segregate it. One possible solution for this problem could separate the waste at the disposal level itself (at house hold level). We have thus come up with an Automated Smart Dust Bin (ASDB) that categorizes the waste as wet, dry, plastic and finally metallics waste. An Arduino Uno forms the heart of the system. This Automated Smart Dust Bin consist of four compartments (for wet, dry, plastic and metal) and it separates all the wastes automatically using below mentioned sensors. [7-9]

Apart from this the bin will have motor for the rotation of the bin according to the type of wastes and a $12 \mathrm{v}$ power supply is used to run this module. Different sensors used in this project are Moisture sensor, IR sensor, Proximity sensor and capacitive sensor. This Automated Smart Dust Bin has a opening on the top of the module which is used to throw the waste into the dust bin and all the sensors will be placed on the opening of the bin.

Here moisture sensors sense the moisture content wastes, if the moisture content is above a preset threshold value then the waste is wet waste, after identifying the wet waste it is thrown into the wet compartment. Inductive proximity sensor can only detect metal targets. They do not detect non- metal targets such as plastics, wood, papers and ceramic. Unlike photoelectric sensors, this allow a inductive proximity sensor to detect a metal object through opaque plastic, after identifying the metal waste it is thrown into the metal compartment. Capacitive sensor are capable of detecting plastic, wood and other raw materials including metals. A common application is the detection of liquid, plastics, and grains after identifying the plastic waste it is thrown into the plastic compartment. And finally the nondetected wastes are detected by the IR sensor and the wastes are thrown into the dry compartment. So that the different kinds of wastes are separated automatically in this ASDB. The bin can help us to dispose the waste properly and efficiently without any problem. Some of the dry, metal wastes can be recycled and the wet waste are converted as manure. This Automated Smart Dust Bin will also notify about the amount of wastes filled through an LED. 


\section{www.rspsciencehub.com}

The bin will also alert by sending a message to phone to tell that it is time to throw the garbage using GSM module. And also consist of a buzzer to alarm if the bin is filled. This idea will help us to dispose the waste in a hygienic manner. Segregation makes it possible to reuse and recycle the waste effectively. Thus implementing our project at household level will reduce the expenditure on waste disposal, manual effort. Thus this idea will help us to dispose the waste in a hygienic manner.

\section{Conclusion:}

The Automated Smart Dust Bin helps us in safer, hygienic way of disposal of the waste. this project ensure that garbage disposal by the human are completely hand-free and hence number contact with the bin is needed. This system has its own limitations. It can segregate only one type of wastes at a time with an assigned priority for metal. Thus improvements can be made to segregate mixed type of wastes.

\section{References:}

[1]. United Nations Environment Programme year book, 2009

[2]. Reverter, Ferran and Gasulla, M and PallasAreny, Ramon. (2003) "Capacitive Level Sensing for Solid- Waste Collection". Proceedings of IEEE Sensors. 2. 7 - 11 Vol.1. 10.1109/ICSENS.2003.1278885.

[3]. [Shubham Thakker, R. Narayanamoorthi, "Smart and Wireless Waste Management" in IEEE Sponsored $2^{\text {nd }}$ International Conference on Innovations in Information Embedded and Communication Systems

[4].A. Chandramohan, J. Mendonca, N. R. Shankar, N. U. Baheti, N. K. Krishnan and M. S. Suma, "Automated Waste Segregator", 2014 Texas Instruments India Edu- cators' Conference (TIIEC), Bangalore, 2014, pp. 1-6. doi: 10.1109/TIIEC.2014.009

[5].Andrei Borozdukhin, Olga Dolinina and Vitaly Pechenkin, "Approach to the Garbage Collection in the Smart Clean City Project" in, Yuri Gagarin State Technical University of Saratov, Saratov, Russia 2016.

[6]. Vishal V, Sayantan Gangopadhyay - Sir M Visvesvaraya Institute of Technology -
"Capacitive Sensors: The Future of Waste Segregation"

[7]. Thompson A.F, Afolayan A.H, Ibidunmoye E.O,"Application of Geographic Information System to Smart Garbage Monitoring and Clearance System using Internet of Things 189 Solid Waste Management" in Pan African International Conference on Information Science, Computing and Telecommunications (2013).

[8]. Atmel "8-bit AVR Microcontroller with 32K Bytes In- System Programmable Flash" ATmega328P [Rev No. 7810D-AVR01/15]

[9]. Abhay Shankar Bharadwaj, Rainer Rego, Anirban Chowdhury, "IoT Based Solid Waste Management System" in Frugal Labs Tech Solutions Private Limited, Bengaluru, Karnataka, India 2016. 